\title{
Quantitative MRI Analysis of Idiopathic Carpal Tunnel Syndrome
}

\section{İdiopatik Karpal Tunel Sendromunda Kantitatif MR Analizi}

\author{
Halil Kamil OGE ${ }^{1}$, Berat ACU², Tacettin GUCER ${ }^{3}$, Tugra YANIK ${ }^{4}$, Safak SALVARLI ${ }^{5}$, Mehmet Murat FIRAT $^{5}$ \\ ${ }_{1}^{1}$ Ankara Guven Hospital, Department of Neurosurgery, Ankara, Turkey \\ ${ }^{2}$ Osman Gazi University, Faculty of Medicine, Department of Radiology, Ankara, Turkey \\ ${ }^{3}$ Ankara Medicana Hospital, Department of Plastic and Reconstructive Surgery, Ankara, Turkey \\ ${ }_{4}^{4}$ Ankara Guven Hospital, Department of Neurology, Ankara, Turkey \\ 5 Ankara Guven Hospital, Department of Radiology, Ankara, Turkey
}

Correspondence address: Halil Kamil OGE / E-mail: koge59@gmail.com

\begin{abstract}
AIM: The aim of this study was to try to find parametric ratios for the diagnosis and pathophysiology of carpal tunnel syndrome using MR. MATERIAL and METHODS: Dominant side wrist MRI examinations of 27 female carpal tunnel patients and 21 normal females were compared. The carpal tunnel contents area / carpal tunnel cross section area ratio was defined, analysed and discussed with the literature.

RESULTS: Carpal tunnel contents / wrist area ratios of the carpal tunnel patients were measured and compared with the control group. This comparison revealed that the proportion of the contents of the carpal tunnel is increased in the carpal tunnel syndrome patients. Palmar bowing was found to be increased and median nerve cross section area was found to be increased at the proximal entrance of the carpal tunnel.

CONCLUSION: As Phalen has postulated, the volume of the contents of the carpal tunnel were found to be increased in the carpal tunnel syndrome patients. Carpal tunnel cross section areas remained the same with the control group. This increase can be demonstrated by MRI imaging which can provide an evidence for the pathophysiology of carpal tunnel syndrome.
\end{abstract}

KEYWORDS: Carpal tunnel syndrome, Area measurement, Ratio

öz

AMAÇ: Bu çalışmanın amacı, el bileği MR incelemesiyle tespit edilen karpal tünel kapsamı/karpal tunel alanı oranları ile karpal tunel sendromuna diagnostik ve patofizyolojik bir yaklaşımda bulunmaktır.

YÖNTEM ve GEREÇLER: 27 karpal tunel hastası kadın ile dominant el bileği MR incelemesi yapılan 21 kadından oluşan kontrol grubunun el bilek MR ları karşılaştırılmıştır. Karpal tunel kapsamı / karpal tunel alanı oranı tanımlanarak bu oran, median sinir alanı ve transverse karpal ligamentteki palmar yaylanma ölçülerek analiz edilmiştir.

BULGULAR: Seride karpal tunel kapsamı/karpal tunel alanı oranında karpal tunel sendromlu hastalarda karpal tunel kapsamı lehinde istatistiksel olarak anlamlı bir artış tespit edilmiştir. Hastalarda karpal tunel proksimal girişinde ölçülen median sinir kesit alanlarında ve transvers karpal ligament palmar yaylanmasında da istatistiksel olarak anlamlı bir artış bulunmuştur.

SONUÇ: Karpal tunel sendromlu hastalarda Phalen'in öne sürdüğü gibi karpal tunel kapsamında kronik travmaya bağlı bir artış tespit edilmiştir. Bu kapsam artışına karşılık karpal tunel yüzey alanlarında anlamlı bir artış tespit edilmemiştir. Bu bulgu MR ile gösterilebilmektedir ve karpal tunel sendromunun fizyopatolojisinin anlaşılması konusunda bir kanıt olabilmektedir.

ANAHTAR SÖZCÜKLER: Karpal tunel sendromu, Alan ölçümü, Oran

\section{INTRODUCTION}

Carpal tunnel syndrome is one of the most common entrapment syndromes of the upper extremity. It is caused by pressure or pressure induced injury on the median nerve in its course when passing through carpal tunnel that is formed by the carpal bones and the flexor retinaculum in the wrist $(7,8)$. This pressure can be caused by the anatomical variations of the carpal tunnel or by increased contents such as ganglion cysts, hypertrophied tendons and ligaments or tenosynovitis due to repetitive trauma of the wrist $(1,6,16)$.
Carpal tunnel syndrome is mostly prevalent in women in their third and fourth decade, and the dominant hand is commonly affected especially in women who are working with their hands $(1,17)$. The most common symptom is tingling pain, cramps and sensory disturbances. Numbness of the fingers especially in the morning may be the leading symptom in most cases. The patient may wake up from her sleep due to severe numbness felt in the affected hand. Wagging the hand may heal the numbness for a while. Motor function loss and thenar atrophy may be observed in advanced cases. Motor loss is limited to the abduction and opposition of the thumb 
$(6,16)$. The carpal tunnel is roughly confined deeply by the carpal bones and superficially by the retinaculum flexorum or the transverse carpal ligament. Retinaculum flexorum is attached to the hook of hamatum and psiformis medially and tuberculum trapezium and scaphoideum laterally (12).

This anatomical tunnel is occupied by nervus medianus and tendons of the flexor muscles of the hand, which originate mainly from the medial epicondyle of the humerus, anterior aspect of radius and ulna and the interosseous membrane. In the superficial plane, the tendons of the flexor carpi radialis are found proximally but when they travel in the tunnel, they pierce the flexor retinaculum and leave the carpal tunnel. After leaving the tunnel, the flexor carpi radialis tendons insert to the base of the second and third metacarpals $(9,12$, 24).

Deeper to the flexor carpi radialis tendons, flexor digitorum superficialis tendons are placed in four separate bundles. After these four tendon groups, flexor digitorum profundus tendons are found in the deeper layer. Lumbrical muscles usually originate distally to the exit of the tunnel $(10,12)$. The median nerve is placed under the flexor retinaculum in the proximal portion of the tunnel. Before entering the carpal tunnel, it gives off the palmar superficial branch that courses outside the carpal tunnel. When traced distally, the median nerve flattens at the level of the os hamatum and it gives its branches near the distal exit $(9,11,19)$.

MR imaging of the carpal tunnel has distinct anatomical landmarks, making it easy to examine. At the proximal entrance of the tunnel, the flexor retinaculum is thin and may be difficult to identify. The flexor retinaculum gets thicker while going distally, and can be visualised in all the scans which are also very distinct at the exit level where the basis of metacarpal bones is visible $(11,12)$.

As the tendons lack mobile protons, they have a weak signal intensity in the MR scans that are seen as dark clusters in the axial scans, which can be easily identified (12). The tendon of the flexor carpi radialis can easily be defined and can be excluded from the carpal tunnel contents when they are traced in the volumetric scans. In the proximal sections, the tendon courses superficial to the scaphoid bone as an ovoid dark bundle. When traced distally, it can be observed in the vertical groove of the trapezium and then inserts to the bases of second and third metacarpal bones $(12,13,24)$.

Superficially the tendons of the flexor digitorum superficialis are easily identified as four superficially travelling dark bundles. The median nerve lies between the flexor digitorum superficialis tendons of the index and long finger and the flexor retinaculum. Tendons of the flexor digitorum superficialis form an arc beneath the flexor retinaculum which makes the superficial boundaries of the carpal tunnel can be traced easily $(11,24)$.

Tendons of the flexor digitorum profundus may not be separated as easy as the superficial ones. They are usually seen in three bundles. As these bundles traced distally they separate and become four bundles $(11,24)$.
Nervus medianus can easily be identified from the dark coloured tendons as it has a similar intensity of muscles. Nervus medianus is located just under the flexor retinaculum. Its long axis is parallel to the flexor retinaculum in most cases. As it is traced distally, median nerve divides into its terminal branches and this anatomical formation can be seen in the most distal part of the carpal tunnel at the level of metacarpal bases $(9,15,19)$.

Characteristic MR findings of the carpal tunnel syndrome is the proximal swelling of the median nerve at the level of pisiformis, flattening of the median nerve at the level of hamatum, increased signal intensity of the median nerve and the arc formation of the retinaculum flexorum. These findings with the complement of EMG can be supportive to the diagnosis. On the other hand, MR findings depend on the comments of the radiologist as there is no parametric value differentiating normal and pathologic wrists, contrary to $\operatorname{EMG}(9,10,12,15,19)$. The aim of this study was to try to find parametric ratios to explain the pathophysiology of carpal tunnel syndrome using MR.

\section{MATERIAL and METHODS}

Twenty-seven female patients who had idiopathic carpal tunnel syndrome were chosen for this trial. Patients who had diabetes, gout, rheumatoid arthritis or any systemic disease, ganglion cysts in the carpal tunnel or who had experienced wrist trauma were excluded from this study. There were only two male patients who had documented carpal tunnel syndrome and they were also excluded as there would not be any statistical significance for their presence in the group.

All patients underwent physical and neurological examination, EMG and MR studies. Direct antero-posterior and lateral wrist $X$ rays were performed on each patient to exclude the malunion of distal radial fractures and bone anomalies that affect carpal tunnel measurements. Patients were examined for positive Phalen's test, positive Tinnel sign at the wrist level, motor and sensory disturbances and an anamnesis was obtained for numbness and paresthesias. After the positive neurological examination and exclusion of the systemic diseases and wrist fractures, the patients underwent nerve conduction studies. Median motor distal latency is considered to be prolonged if it is more than $4.4 \mathrm{msec}$ at $7 \mathrm{~cm}$ and the syndrome is considered to be severe when the distal motor latency is more than $4.6 \mathrm{msec}$. The patients in our group has distal motor latencies of more than $4.6 \mathrm{msec}$ which can be classified as severe carpal tunnel syndrome $(2,3,17,20)$. The control group was composed of 21 female patients' dominant side wrists that had no complaints and examination findings of carpal tunnel syndrome.

MRI of the carpal tunnels was performed to the affected dominant hands of the carpal tunnel patients and the dominant hands of the control group. 1.5 Tesla GM and Hitachi Eshelon systems with wrist coils are used with the wrist in prone and neutral position. MRI protocols included axial spin echo T1, fast spin echo $\mathrm{T} 2$ with fat saturation, proton 
density-weighted with fat saturation and 3D FIESTA images, coronal spin echo T1, proton density weighted with fat saturation, fast spin echo T2 with fat saturation images, and sagittal proton density-weighted with fat saturation images. Parameters of the wrist MRI were as follows: TR/TE $=400 / 17$ or $660 / 15$ (T1-weighted image), $3400 / 46$ or $2400 / 37$ (proton density weighted image with fat saturation), 3500/90 (T2weighted image with fat saturation), a 3-mm slice thickness, a 0.3-mm intersection gap, a 10 or 12 - cm field of view (FOV), 2 or 3 number of excitations (NEX) and a $256 \times 256$ or $320 \times 256$ matrix. The axial 3D FIESTA image parameters were as follows: $\mathrm{TR} / \mathrm{TE}=7.2 / 2.3,1.25$ - $\mathrm{mm}$ slice thickness, 0.5- $\mathrm{mm}$ intersection gap, 10-cm FOV, 2 NEX, 320 x 256 matrix.

Four sections of the wrist were identified. The first section is the proximal section in which the distal radioulnar joint is seen. This section is the distalmost part of the median nerve just before entering the carpal tunnel. The second section is the proximal (entrance) of the carpal tunnel, which is at the middle of os pisiformis (Figure 1A, B). For standardisation, the thickest section of the pisiformis was chosen. Carpal tunnel borders were marked using the transverse carpal ligament at the superficial (ventral) part, laterally by the capitotrapezial ligament and the scaphoid, medially by the pisiform, and dorsally (deep) by the carpal bones and the intercarpal ligament.

The third section is the middle part of the carpal tunnel where the os hamatum is the landmark. At this level the carpal tunnel is bounded anteriorly by the transverse carpal ligament, laterally by the capitotrapezial ligament and os scaphoideum, medially by the hook of hamatum, and dorsally by the carpal bones and the intercarpal ligaments (Figure 2A, B).

Fourth section is the section where the proximal metacarpal bones start to be seen (Figure 3A, B).

Palmar bowing of the transverse carpal ligament was measured as the length of the perpendicular line drawn from
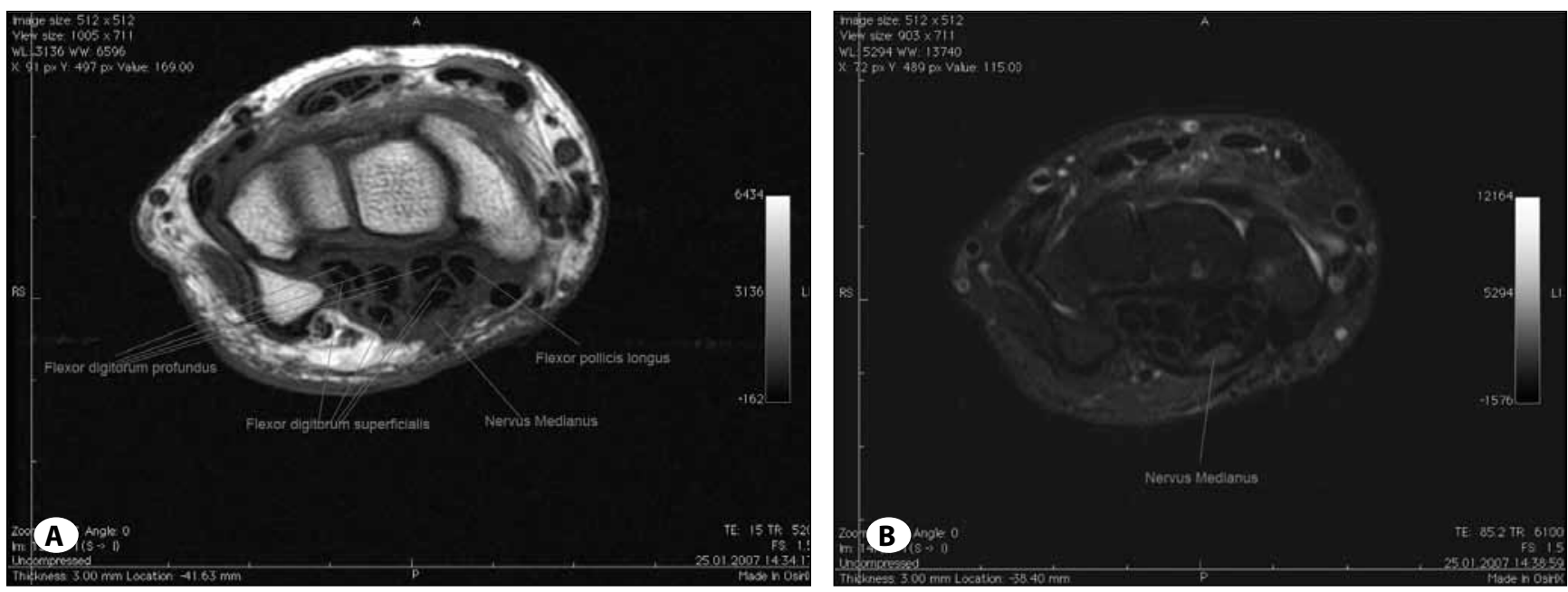

Figure 1: A) Proximal entrance of the carpal tunnel at the level of os pisiformis (T1 spin echo images). B) Proximal entrance of carpal tunnel at the level of os pisiformis showing nervus medianus (T2 fat-sat images).
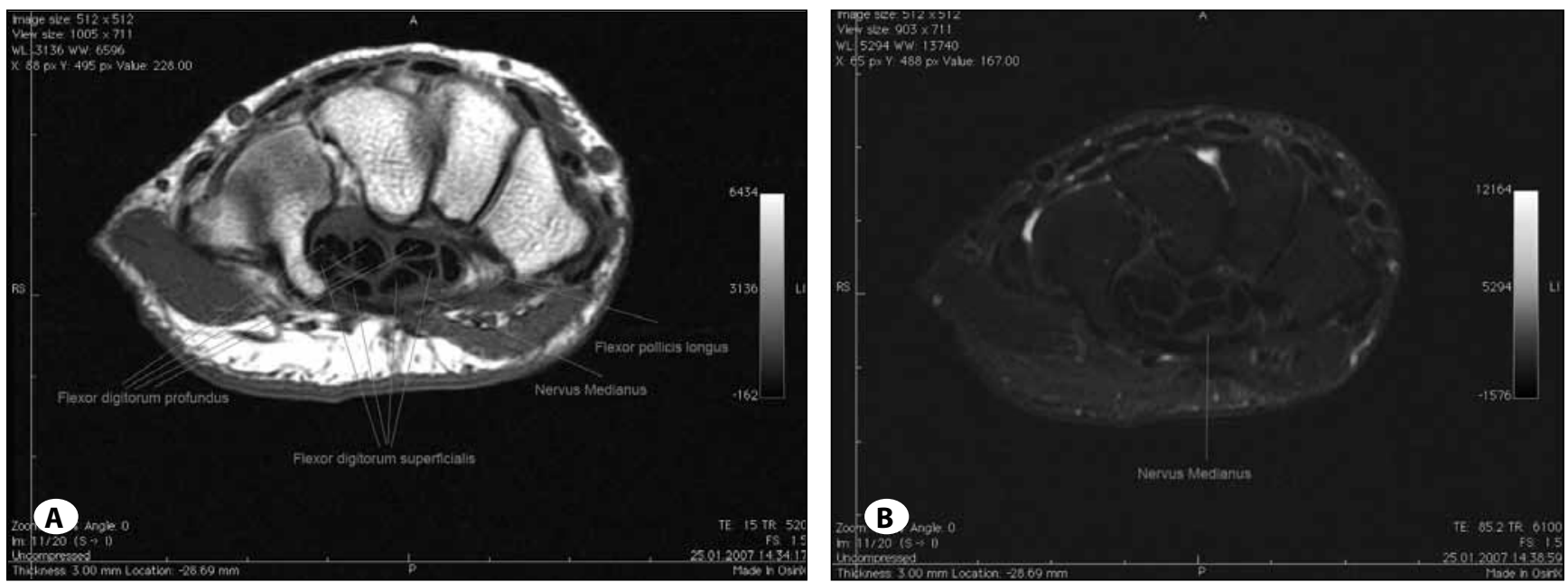

Figure 2: A) Middle portion of the carpal tunnel at the level of hamatum (T1 spin echo images). B) Middle portion of the carpal tunnel at the level of hamatum showing nervus medianus (T2 fat-sat images). 

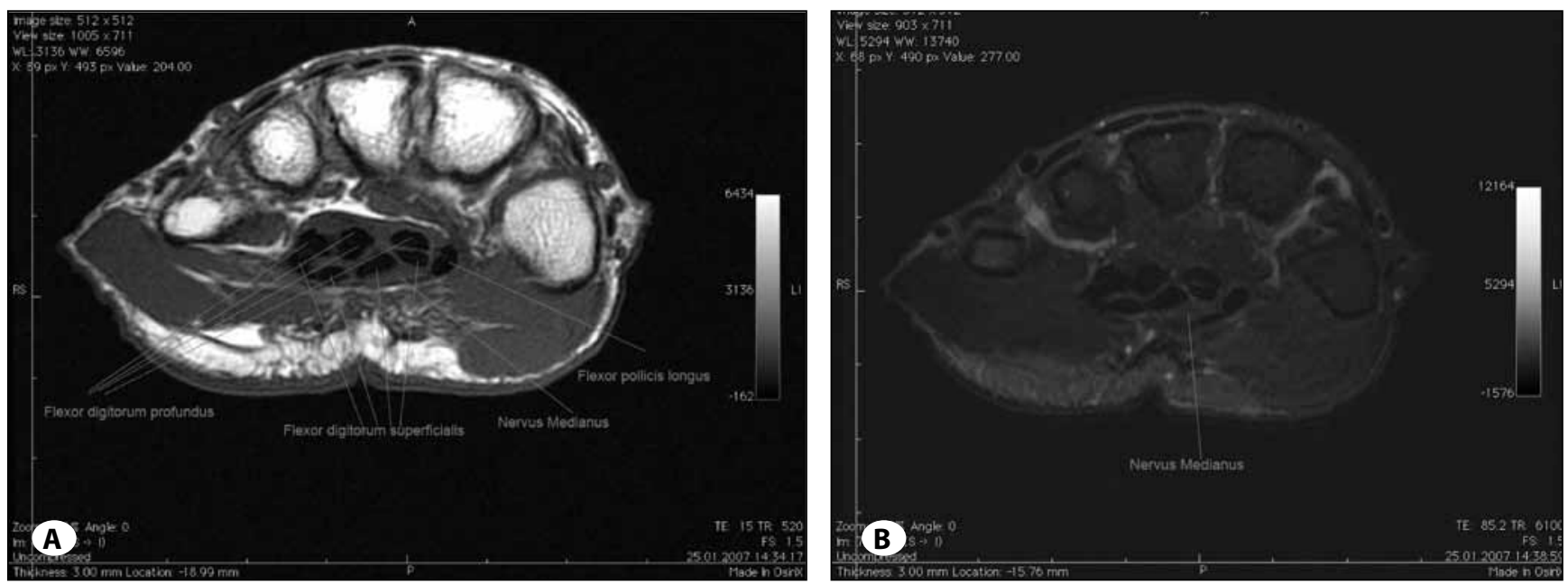

Figure 3: A) Distal (exit) of carpal tunnel at the level of proximal metacarpal bones (T1 spin echo images). B) Distal (exit) of carpal tunnel at the level of proximal metacarpal bones showing nervus medianus (T2 fat-sat images).

the apex of the bowing to the straight line joining the hook of hamate and trapezium at the third section.

The carpal tunnel and contents were traced and the palmar bowing was measured by using the Osirix Imaging Software, which is an open source freeware for Macintosh computers certified to use for research purposes. MRI images in the DICOM format were transferred to a MacBook Pro computer and by using the landmarks mentioned above the boundaries of the carpal tunnel and carpal tunnel contents were traced and the areas were measured without having the clinical and EMG findings and diagnosis of the corresponding patients. These data were transferred to Microsoft Excel 2011 and using its database and statistical analysis programs the statistical analyses were performed. Ratios of the carpal tunnel contents and the carpal tunnel areas of the second, third and fourth levels were determined and statistical analyses were done by using the $\mathrm{t}$ test.

\section{RESULTS}

The patient and control groups are all composed of female patients. 27 subjects were in the patient group (mean age is 46 years $(S D=13.4)$ ) and 21 were in the control group (mean age is 49 years $(S D=11.7))$.

Carpal tunnel contents/carpal tunnel area ratios, and the $p$ values (Student's $t$ Test) of differences between the patient and control groups are presented in Table I.

Carpal tunnel areas measured at the levels of os pisiformis (proximal), os hamatum and basis metacarpi (distal) are presented and the $p$ values (Student's t Test) of the differences between the patient and control groups are presented in Table II (square centimeters).

Median nerve cross-section areas at the entrance were analysed between control and patient groups. The mean cross-section area of the patient group was found to be 15.58 $\pm 0.84 \mathrm{sq} \mathrm{mm}$ while the mean cross-section area of the nerve
Table I: Carpal Tunnel Contents/Carpal Tunnel Area Ratios

\begin{tabular}{|l|c|c|l|} 
& Patient & Control & p value \\
\hline Proximal & $0.6054 \pm 0.044$ & $0.5245 \pm 0.038$ & 0.00004 \\
\hline Hamatum & $0.6063 \pm 0.058$ & $0.5443 \pm 0.06$ & 0.0011 \\
\hline Distal & $0.0590 \pm 0.061$ & $0.5529 \pm 0.053$ & 0.036
\end{tabular}

Table II: Carpal Tunnel Area Measurements of Three Standard Levels

\begin{tabular}{|l|c|c|c|}
\hline & Patient & Control & p value \\
\hline Proximal & $1.6288 \pm 0.21$ & $1.5641 \pm 0.21$ & 0.3213 \\
\hline Hamatum & $1.5717 \pm 0.19$ & $1.4998 \pm 0.22$ & 0.2338 \\
\hline Distal & $1.5874 \pm 0.18$ & $1.5119 \pm 0.25$ & 0.2445 \\
\hline
\end{tabular}

in the conrol group was found to be $9.8 \pm 0.29 \mathrm{sq} \mathrm{mm}$ which is statistically significant $(p<0.001)$. Median palmar bowing length was measured as $2.3146 \pm 0.6528 \mathrm{~mm}$. which was $1.1273 \pm 0.7492 \mathrm{~mm}$. in the control group and statistically significant $p<0.0016$

\section{DISCUSSION}

Carpal tunnel syndrome is known as the most common nerve entrapment syndrome. It usually occurs between ages of 35 and 60 and women are prominently affected. The incidence of the carpal tunnel syndrome varies from 125 to $515 / 10000$ with overall prevalence of $220 / 100000$. It is a chronic disabling syndrome that presents itself with numbness and nocturnal paresthesias of the fingers innervated by the median nerve. Sensory loss and thenar atrophy develops in advanced cases (18).

The gold standard for the diagnosis of carpal tunnel is electrophysiologic demonstration of the median nerve dysfunction with ENMG (20). ENMG has high sensitivity and specificity for the diagnosis of carpal tunnel syndrome. On the other hand, ENMG does not give any knowledge about 
the pathologic anatomy of the syndrome. MRI of the wrist clearly gives information about the condition of the nerve, thickness of the transverse carpal ligament, tenosynovitis of the tendons and the bony structure of the carpal tunnel (6, $17,18)$.

Phalen proposed that thickening due to the fibrosis of the synovium is the main cause of the carpal tunnel syndrome. According to Phalen, the increase of ligament volume that was the result of chronic friction trauma of the ligaments in the carpal tunnel is the cause of carpal tunnel volume/content incompatibility that raises the carpal tunnel pressure (16). The increase of carpal tunnel pressure affects microcirculation in the median nerve that causes edema. Chronic epineural edema of the median nerve causes fibroblast invasion leading to scar formation within the median nerve. This is the cause of neural tissue compression within the nerve. Proximal to the scar formation, swelling that was caused by the edema; blockage of the axoplasmic flow and fibroblast infiltration is seen (21). Although interobserver variations have been demonstrated, an increase in the volume of synovia and the interspace between the tendons were measured that provide MR evidence supporting Phalen's proposal $(3,23)$.

There is inconsistency in the literature regarding the carpal tunnel area and content volume in carpal tunnel syndrome. Findings of narrower carpal tunnel areas in the severe carpal tunnel syndrome dominate the literature $(13,14)$. There are also controversial results in which the carpal tunnel volume is similar to controls or larger in carpal tunnel syndrome (17, 21). Our findings also showed a decrease of carpal tunnel area when traced distally but the differences of the areas do not show any significance statistically (table 2). This finding is also contrary to our previous measurements that were done by using the CT scan (14). In that study, the bony boundaries of the carpal tunnel were measured by CT scans, but we used the ligaments and capsules surrounding the carpal tunnel to measure the carpal tunnel areas in this study and we believe this to be more precise. Even if statistically insignificant, the carpal tunnel areas of the patient group was measured to be larger than the control group. This may just be a coincidence but it can also be postulated that the bowing caused by the raised pressure in the carpal tunnel is responsible for the slight increase of the carpal tunnel area. The mean distance measured by the bowing of the transverse carpal ligament was found to be $2.3146 \pm 0.6528 \mathrm{~mm}$. in the carpal tunnel group and $1.1273 \pm 0.7492 \mathrm{~mm}$. in the controls.

Carpal tunnel cross-section areas of the corresponding levels had no statistically significant difference between the patient and control groups. There is inconsistency in the literature about this finding. Some show increased carpal tunnel cross section areas in the carpal tunnel syndrome group (22), but some have found no difference or smaller carpal tunnel cross section areas in carpal tunnel patients $(10,13,14,23)$. Carpal tunnel areas measured in our series were found to be larger than the control group in all sections but the difference was found to be statistically insignificant, and therefore this paper is also in the no difference group. As the boundaries of the carpal tunnel is made of non elastic material such as carpal bones, intercarpal ligaments and the transverse carpal ligament, increased ratio of the contents are hardly compensated causing an increase of the carpal tunnel pressure which was demonstrated previously $(1,7,16)$ This proportional increase causing elevated carpal tunnel pressure can be demonstrated by the bowing of the transverse carpal ligament.

Monagel et al. and Cobb et al. measured the carpal tunnel content areas and correlated volumes. Monagel et al. found no relation with the carpal tunnel contents volume with the carpal tunnel syndrome while Cobb et al. showed a positive correlation with the carpal tunnel contents volume and the respective carpal tunnel volume. As the numbers of analysed wrists were small it is hard to reach a definitive conclusion from either group. Uchiama et al. measured the interspace volume of 105 carpal tunnel and 36 control patients and found that the volume of the connective tissue of the affected wrists was smaller than the control group. As their measurements were the absolute values obtained from the wrist MRI's, the values had a big variance because of the personal anatomical differences and each author commented that there are big variations in each group. They also did not discuss Phalen's theory of increased synovial and tendon volumes and instead commented on the congenital susceptibility to carpal tunnel syndrome and reported that more work has to be done for this purpose $(4,13,21)$.

In this study, we calculated carpal tunnel contents ratio which is the ratio of carpal tunnel contents area and carpal tunnel contents area in standardized sections. With this ratio we tried to avoid the individual anatomic variations and obtained a more homogenous group not affected by the individual anatomical variations compared to the previous authors.

We measured tendon areas of the standardized sections of wrists and the carpal tunnel areas of the corresponding levels and calculated the ratio of these corresponding levels. According to our results, the contents area / carpal tunnel area ratios were found to be increased in the carpal tunnel patients group and this increase is statistically significant in all three standardized cross sections (table 1). On the other hand, carpal tunnel cross section areas, which is the denominator of the ratio, showed no statistically significant difference from the controls (table 2). This means that the sum of the areas of ligaments and median nerve is proportionally increased in the patient group while the carpal tunnel cross-section areas of the corresponding levels did not increase as much as the contents area increase. This relative increase of the carpal tunnel contents may be the cause of rise in the carpal tunnel pressure as Phalen has postulated previously (16).

Bowing of the transverse carpal ligament was measured by the description of Uchiyama et al. at the hamatum-trapezium (level 3) level (21). Palmar bowing was measured as $2.3146 \pm$ $0.6528 \mathrm{~mm}$. in the patient group while it was $1.1273 \pm 0.7492$ $\mathrm{mm}$. in the control group and the difference was found to be 
statistically significant $(p<0.0016)$. Palmar bowing may be the cause of slight increase of the carpal tunnel cross-section areas of the patient group. Carpal tunnel cross section areas were found to be raised in the carpal tunnel group if compared with the control group in all sections but the difference was found to be statistically insignificant.

Nervus medianus swelling at the entrance of the carpal tunnel is one of the major defined MRI findings of carpal tunnel syndrome, which was also found in our group. The crosssection area of nervus medianus was found to be $9.8 \pm 0.29$ sq $\mathrm{mm}$ in the control group, and $15.58 \pm 0.84$ sq. $\mathrm{mm}$ in the patient group, and the difference was statistically significant $(p<0.001)$. This finding also supports that the raised carpal tunnel contents block the axoplasmic flow which causes the proximal swelling of the nerve descried as a pseudoneuroma $(2,5,9,19)$.

Our findings support Phalen's postulate of idiopathic carpal tunnel syndrome pathophysiology. When the anatomical variations are compensated by calculating the contents area / carpal tunnel area ratio, we found that the proportion of carpal tunnel contents (flexor tendons and nervus medianus) increased relative to the carpal tunnel in the carpal tunnel syndrome group. With the available imaging sequences, the changes in the supportive tissue of the carpal tunnel cannot be visualised and their contribution to carpal tunnel syndrome cannot be demonstrated radiologically. As some variations were observed within the relatively uniform group, there could be differences in pathophysiology inside the carpal tunnel of individuals. Further investigations, new MRI sequences or new radiological modalities will help us to understand the underlying pathology of those variations more precisely.

\section{REFERENCES}

1. Arminio JA: Etiology of carpal tunnel syndrome. Del Med J 58(3):189-192, 1986

2. Beltran J, Rosenberg ZS: Diagnosis of compressive and entrapment neuropathies of the upper extremity: Value of MR imaging. AJR 163: 525-531, 1994

3. Britz GW, Haynor DR, Kuntz C, Goodkin R, Gitter A, Kliot M: Carpal tunnel syndrome: Correlation of magnetic resonance imaging, clinical, electrodiagnostic, and intraoperative findings. Neurosurgery 37(6):1097-1103, 1995

4. Cobb TK, Bond JR, Cooney WP, Metcalf BJ: Assessment of the ratio of carpal contents to carpal tunnel volume in patients with carpal tunnel syndrome: A preliminary report. J Hand Surg Am 22 (4): 635-639, 1997

5. Cudlip SA, Howe FA, Clifton A, Schwartz MS, Bell BA: Magnetic resonance neurography studies of the median nerve before and after carpal tunnel decompression. J Neurosurg 96: 1046-1051, 2002

6. Franzblau A, Werner RA: What is Carpal tunnel syndrome? JAMA 282 (2): 186-187, 1999

7. Gelberman $\mathrm{RH}$, Hergenroeder PT, Hargens AR, Lundborg GN, Akeson WH: The carpal tunnel syndrome. A study of carpal cannal pressures. J Bone Joint Surg Am 63(3): 380-383, 1981
8. Hart AM, Wiberg M: Nerve compression and mechanical neuropathy: Neuropathology. Curr Orthopaed 15:245-248, 2001

9. Ikeda K, Haughton VM, Ho KC, Nowicki BH: Correlative MRAnatomic study of the median nerve. AJR 167:1233-1236, November 1996

10. Mesgarzadeh M, Schneck CD, Bonakdarpour A, Mitra A, Conaway D: Carpal tunnel: MR imaging Part II. Carpal tunnel syndrome. Radiology 171: 749-754, 1989

11. Mesgarzadeh M, Schneck CD, Bonakdarpour A: Carpal tunnel: MR imaging Part I. Normal anatomy. Radiology 171: 743-748, 1989

12. Middleton WD, Kneeland BJ, Kellman GM, Cates JD, Sanger JR, Jesmanowicz A, Froncisz W, Hyde JS: MR imaging of the carpal tunnel: Normal anatomy and preliminary findings in the carpal tunnel syndrome. AJR 148: 307-316, 1987

13. Monagle K, Guangping D, Ansel C, Burnham RS, Snyder RE: Quantitative MR imaging of carpal tunnel syndrome. AJR 172: 1581-1586, 1999

14. Oge K, Demirkazik FB, Nurlu G, İnci S, Erbengi A: Carpal tunnel cross section area measurements in carpal unnel syndrome. Turkish Neurosurgery 4:153-156, 1994

15. Pasternack II, Malmivaara A, Tervahartiala P, Forsberg $H$, Vehmas T: Magnetic resonance imaging findings in respect to carpal tunnel syndrome. Scand J Work Environ Health 29(3): 189-196, 2003

16. Phalen GS: The carpal-tunnel syndrome. Clinical evaluation of 598 hands. Clin Orthop 83: 29-40, 1972

17. Pierre-Jerome C, Bekkelund SI, Mellgren SI, Torbergsen T: Quantitative magnetic resonance imaging and the electrophysiology of the carpal tunnel region in floor cleaners. Scand J Work Environ Health 22:119-123, 1996

18. Radack DM, Schweitzer ME, Taras J: Carpal tunnel syndrome: Are the MR findings a result of population selection bias? AJR 169:1649-1653, 1997

19. Skie M, Zeiss J, Ebraheim NA, Jackson WT: Carpal tunnel changes and median nerve compression during wrist flexion and extension seen by magnetic resonance imaging. J Hand Surg 15A: 934-939, 1990

20. Stevens JC: AAEE minimonograph \#26: The electrodiagnosis of carpal tunnel syndrome. Muscle Nerve 10: 99-113, 1987

21. Uchiyama $S$, Itsubo T, Yasutomi T, Nakagawa H, Kamimura $M$, Kato H: Quantitative MR of the wrist and nerve conduction studies in patients with idiopathic carpal tunnel syndrome. J Neurol Neurosurg Psychiatry 76:1103-1108, 2005

22. Winn FJ Jr, Habes DJ: Carpal tunnel area as a risk factor for carpal tunnel syndrome. Muscle Nerve 13:254-258, 1990

23. Zagnoli F, Andre V, Le Dreff P, Garcia JF, Bellard S: Idiopathic carpal tunnel syndrome. Clinical, electrodiagnostic, and magnetic resonance imaging correlations. Rev Rhum 66(4): 192-200, 1999

24. Zeiss J, Skie M, Ebraheim N, Jackson WT: Anatomic relations between the median nerve and flexor tendons in the carpal tunnel: MR evaluation in normal volunteers AJR 153: 533-536, 1989 